\title{
EFFECTS OF FERTILIZATION ON SOIL WATER USE EFFICIENCY AND CROP YIELD ON THE LOESS PLATEAU, CHINA
}

\author{
LIU, Q. $.^{1,2}-$ MU, X. M. ${ }^{1,3^{*}}-$ ZHAO, G. J. ${ }^{1,3}-$ GAO, P., ${ }^{1,3}$ SUN, W. Y. ${ }^{1,3}$ \\ ${ }^{1}$ State Key Laboratory of Soil Erosion and Dryland Farming on Loess Plateau, Institute of Soil \\ and Water Conservation, Chinese Academy of Sciences and Ministry of Water Resources, \\ Yangling 712100, China \\ (phone: +86-182-9424-2365) \\ ${ }^{2}$ University of Chinese Academy of Sciences, Beijing 100049, China \\ ${ }^{3}$ State Key Laboratory of Soil Erosion and Dryland Farming on Loess Plateau, Institute of Soil \\ and Water Conservation, Northwest A\&F University, Yangling 712100, China \\ *Corresponding author \\ e-mail/phone: xтmu@ms.iswc.ac.cn/ +86-135-7226-5988 \\ (Received ; accepted )
}

\begin{abstract}
The selection of appropriate fertilizers influences agricultural production, especially in waterlimited conditions such as those on the Loess Plateau (China). In this study, we aimed to determine the optimum method for the fertilization of dryland crops. In a two-year split-plot experiment, we tested eight fertilization treatments with different combinations of organic and inorganic fertilizers and a no-fertilizer control. Crop yield, soil water storage, and soil water use efficiency (WUE) were assessed pre-sowing and post-harvest in 2017 and 2018. The results showed that soil water storage was decreased by fertilization, while the WUE and crop yield were both increased: compared to the control, WUE was 6$39 \%$ higher in 2017 and 8-39\% higher in 2018, while crop yield was 3-21\% higher in 2017 and $1-19 \%$ higher in 2018. The maximum effect on WUE and crop yield was achieved when a combination of organic fertilizer and either nitrogen or phosphate fertilizer was applied. Linear regression analysis revealed that soil water consumption (ET) was significantly positively correlated with crop yield. Our results provide a scientific basis for rational crop fertilization on the Loess Plateau and suggest that a combination of organic and inorganic fertilizers is the most appropriate.
\end{abstract}

Keywords: inorganic fertilization, organic fertilization, agricultural production, soil water storage, rainfed agricultural

\section{Introduction}

In the world's typical traditional dry farming regions, scarce precipitation and insufficient water for irrigation have become the main factors limiting the improvement of agricultural productivity (Hamdy, 2003). Different soil water and fertilizer conditions are known to have important effects on crop growth, dry matter distribution, and crop yield (Yan, 2015). For instance, insufficient soil water affects the synthesis and transport of nutrients, reducing crop yield and quality, while inadequate fertility can affect soil water absorption and utilization (Zhang et al., 2007; Wu et al., 2019). The availability of soil water has complex interactions with soil microbial activities, soil physics and chemistry, and plant physiological and biochemical processes. In addition, soil water and fertilizers are important material resources in agricultural production. Therefore, the study of the relationship between fertilization and soil water is a key research area in crop yield and agricultural economic development (Huang, 2010). 
Improving crop yield and soil water use efficiency (WUE) through rational fertilization strategies under water-limited conditions is a hot research topic (Guo et al., 2019). Many studies have shown that the effects of the addition of soil water and the application of fertilizer on crop yield are strongly dependent on the pre-existing soil water and fertility (Fan et al., 2005).

Some studies in the Loess Plateau have found that the effect of fertilization on crop yield is more significant when the soil's natural water level is low. With the improvement in soil fertility, soil water also increased, suggesting that soil water and fertilizer have a coupling effect on crop yield (Krbel et al., 2012; Tang et al., 2016). In another study, fertilizer application boosted soil WUE under all soil water conditions, but especially when soil water levels were already sufficient (Xue, 2009; De, 2013). Compared with the non-fertilization treatment, crop yield increased significantly when fertilized, but the yield difference was not obvious under drought conditions (Tahir, 2012). Soil water and fertilization have also been shown to have extremely significant effects on crop soil water consumption and soil WUE (Tang et al., 2016). Fertilization can significantly inhibit plant transpiration and soil water loss, increase the drought resistance and soil water consumption of crops, and increase soil WUE (Laxminarayana et al., 2011; Belay, 2002) Fertilization can also reduce the consumption of ineffective water in the soil, increase the water utilization rate, and boost the crop's ability to use the deep-layer soil water (Chen et al., 2016; Ren et al., 2019).

The Loess Plateau is a typical traditional dry farming region; it is located in a semiarid/semi-humid climate zone and has undergone serious soil erosion. Due to the low precipitation level, its uneven seasonal distribution, and the low soil organic matter content, nutrients and moisture have become the key factors restricting agricultural production in the area. Precipitation is a natural event which determines the fluctuation in dryland crop yield. Careful fertilization that correctly influences the soil nutrient cycle can ensure high nutrient uptake of the crops and enhance soil fertility. Conversely, excessive fertilization has a limited effect on increasing yield and undermines the soilcrop system nutrient balance. Despite the importance of this issue in the Loess Plateau region, there are few reports that have directly looked at the relationship between fertilization and WUE in this area.

Our objective was to fill this gap in knowledge and to achieve a science-based recommendation for the fertilizer that is the most appropriate to the drylands on the Loess Plateau. In this study, we report the changes in crop yield and WUE under different fertilization scenarios in two consecutive years in which different crops were planted on the same study plots. We hypothesized that (1) fertilization would significantly increase soil water storage, WUE, and crop yield; and (2) the impact of an organic fertilizer would be higher than that of inorganic fertilizer.

\section{Materials and methods}

\section{Basic geographic information and experimental soil conditions}

The field experiment was conducted in 2017 and 2018 at a study site located in the middle of the Loess Plateau $\left(36^{\circ} 51^{\prime} \mathrm{N}, 109^{\circ} 18^{\prime} \mathrm{E}\right)$. The site (Fig. 1) is located $1068 \mathrm{~m}$ above sea level; it has a mean annual temperature of $8.8^{\circ} \mathrm{C}$ and an annual precipitation level of $500.0 \mathrm{~mm}$ in the last 10 years. The recorded annual precipitation was $557.6 \mathrm{~mm}$ in 2017 and $536.3 \mathrm{~mm}$ in 2018. The precipitation during the growth period (between March and September) was $443.1 \mathrm{~mm}$ in 2017 , accounting for $79.47 \%$ of the total 
annual precipitation; the respective values were $503.1 \mathrm{~mm}$ and $93.8 \%$ in 2018 . The climate details are shown in Figure 2. The soil type at the study site was loess soil; basic soil physical and chemical properties were measured at the depth of $0-40 \mathrm{~cm}$ before sowing in two years of experimentation (Table 1).

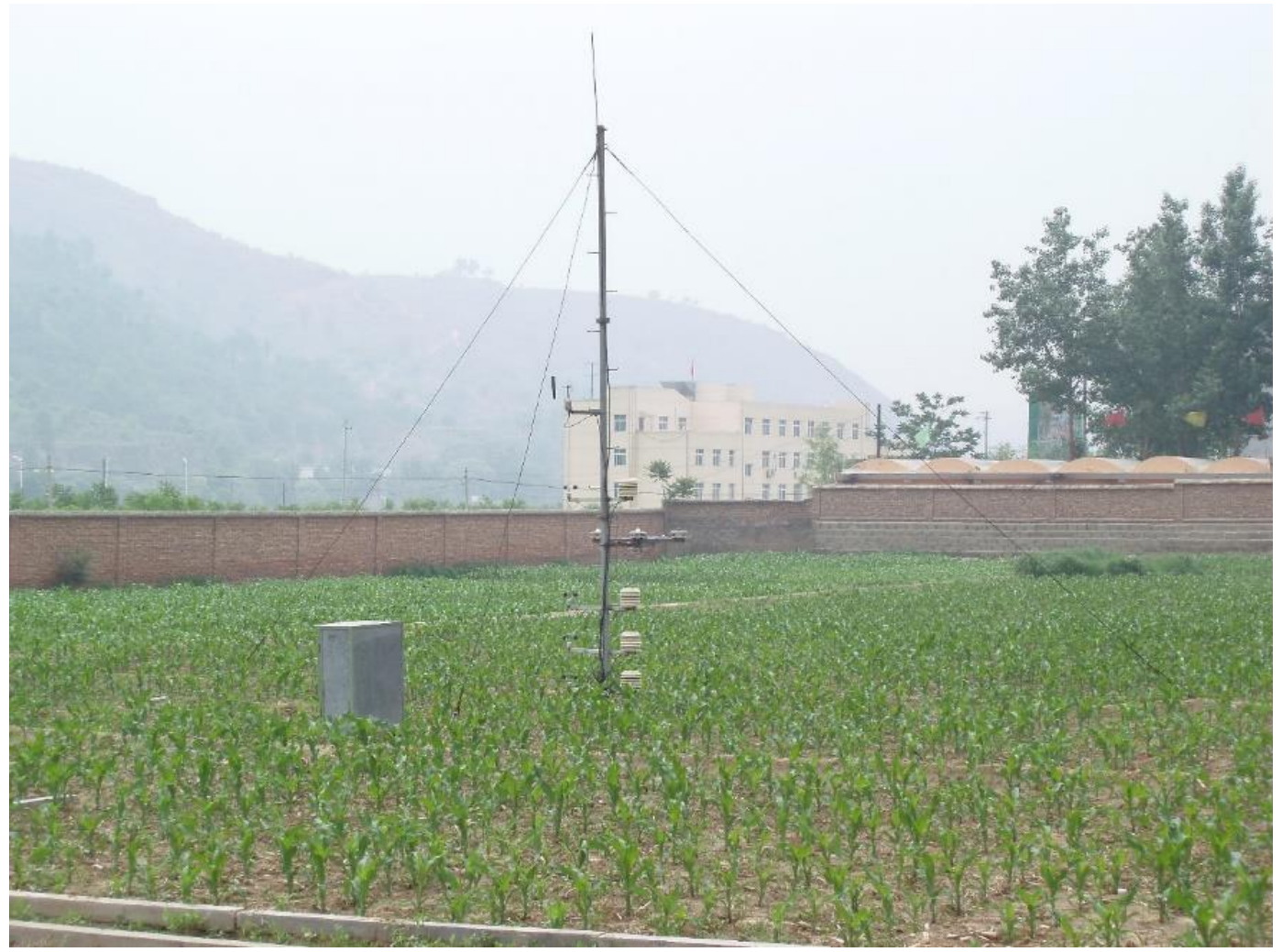

Figure 1. The test field

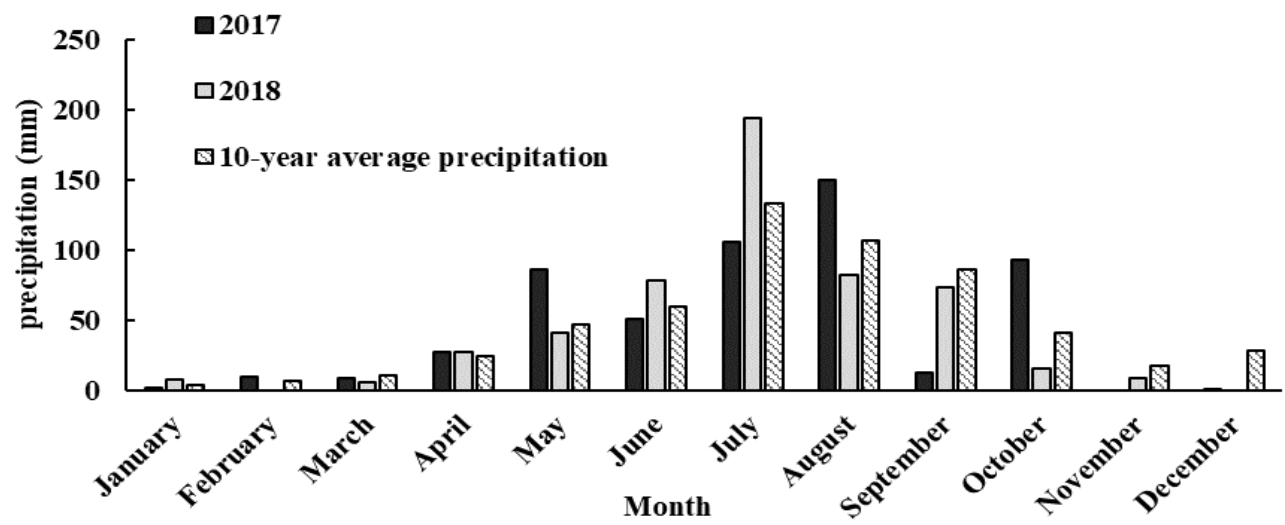

Figure 2. Average monthly precipitation in Ansai County between 2017 and 2018

Table 1. Basic physical and chemical properties of soil (0-40 cm soil layers)

\begin{tabular}{c|c|c|c|c|c}
\hline Year & Bulk density & SOM & TN & TP & pH \\
\hline 2017 & 1.327 & 4.053 & 0.217 & 0.422 & 8.31 \\
2018 & 1.334 & 4.123 & 0.196 & 0.478 & 8.32 \\
\hline
\end{tabular}




\section{Fertilizer treatments}

Organic and inorganic fertilizers were used. The nitrogen fertilizers $(\mathrm{N})$ were urea and diammonium phosphate, the phosphate fertilizer $(\mathrm{P})$ was diammonium phosphate, the potassium fertilizer $(\mathrm{K})$ was potassium chloride, and the organic fertilizer $(\mathrm{M})$ was sheep manure. Organic fertilizer treatments were the following: M, MN, MP, and MNP. Inorganic fertilizer treatments were NP, NK, PK, and NPK. In addition, a no-fertilizer treatment was used as the control CK. The fertilizers were spread evenly on the soil surface before sowing. Nine fertilization practices are shown in Table 2.

Table 2. Experimental fertilization

\begin{tabular}{c|c}
\hline Treatment & Illustration \\
\hline M & Sheep manure $\left(0.75 \mathrm{~kg} / \mathrm{m}^{2}\right)$ \\
MN & Sheep manure $\left(0.75 \mathrm{~kg} / \mathrm{m}^{2}\right)+$ Urea $0.021 \mathrm{~kg} / \mathrm{m}^{2}$ \\
MP & Sheep manure $\left(0.75 \mathrm{~kg} / \mathrm{m}^{2}\right)+$ Diammonium phosphate $\left(0.017 \mathrm{~kg} / \mathrm{m}^{2}\right)$ \\
MNP & Sheep manure $\left(0.75 \mathrm{~kg} / \mathrm{m}^{2}\right)+$ Urea $\left(0.021 \mathrm{~kg} / \mathrm{m}^{2}\right)+$ Diammonium phosphate $\left(0.017 \mathrm{~kg} / \mathrm{m}^{2}\right)$ \\
NP & Urea $0.021 \mathrm{~kg} / \mathrm{m}^{2}+$ Diammonium phosphate $\left(0.017 \mathrm{~kg} / \mathrm{m}^{2}\right)$ \\
NK & Urea $\left(0.021 \mathrm{~kg} / \mathrm{m}^{2}\right)+$ Potassium sulfate $\left(0.012 \mathrm{~kg} / \mathrm{m}^{2}\right)$ \\
PK & Diammonium phosphate $\left(0.017 \mathrm{~kg} / \mathrm{m}^{2}\right)+$ Potassium sulfate $\left(0.012 \mathrm{~kg} / \mathrm{m}^{2}\right)$ \\
NPK & Diammonium phosphate $\left(0.017 \mathrm{~kg} / \mathrm{m}^{2}\right)+$ Urea $\left(0.021 \mathrm{~kg} / \mathrm{m}^{2}\right)+$ Potassium sulfate $\left(0.012 \mathrm{~kg} / \mathrm{m}^{2}\right)$ \\
CK & No fertilizer \\
\hline
\end{tabular}

\section{Experiment design}

Local heat and moisture conditions allow crops to only grow once a year. The planting mode used millet-soybean rotations, so millet was sowed on May 2 in 2017, and soybeans on May 4 in 2018. The millet cultivar was Hongyang 7. The soybean variety planted was Zhonghuang 35. Millet sowing in 2017 was quantitative sowing, planting density was 15 plants $/ \mathrm{m}^{2}$. The sowing method was drill, spraying $10 \%$ Monosulfuron $0.023 \mathrm{~kg} / \mathrm{m}^{2}$ on May 24 for chemical weeding in the experimental plot. In 2018, soybean planting density was 22 plants $/ \mathrm{m}^{2}$. At the end of May, when two compound leaves of soybean were grown after seedling emergence, 5\% imazethapyr $0.0001 \mathrm{~kg} / \mathrm{m}^{2}$ was applied to soybean to remove weeds. Each of the 9 treatments was allocated 4 plots, yielding a total of 36 plots. Each plot was $3.5 \mathrm{~m}$ long and $8.57 \mathrm{~m}$ wide (plot area of $30 \mathrm{~m}^{2}$ ). The plots were arranged in random blocks (Fig. 3). The soil fertility and environmental conditions in all plots were uniform. Organic, potash, and phosphate fertilizers were each applied once, while urea fertilizer was applied at a rate of $136 \mathrm{~g}$ per plot, and the remaining $500 \mathrm{~g}$ nitrogen fertilizer was applied during the flowering period. The millet was fertilized with urea on April $27^{\text {th }}$, 2017, and supplementary nitrogen fertilizer was added on July $3^{\text {rd }}, 2017$. Urea fertilizer was added to soybeans on April $28^{\text {th }}, 2018$, and supplementary nitrogen fertilizer was added on July $26^{\text {th }}, 2018$. The 9 fertilization treatments are shown in Figure 3.

\section{Soil sampling and crop harvesting}

Soil sample collection method: Taking each plot as a unit, the soil sampling point was more than $1 \mathrm{~m}$ of the boundary of the sample plot. Sampling points were randomly selected forming an S shape. Surface debris was then removed, and soil samples were collected. All soil samples from the same sampling point were combined and passed 
through a $2 \mathrm{~mm}$ sieve. Samples were stored and labelled after the relevant sampling information had been recorded. In all plots, the soil water level was measured every $10 \mathrm{~cm}$ up to the depth of $100 \mathrm{~cm}$ with a neutron moisture meter (Neutron moisture meter, Model CS830, Rurui Technology Company, Guangzhou, China). The weight water consumption was multiplied by the soil bulk density to obtain the volumetric water consumption (Wang et al., 2016). The soil water consumption was determined using the oven-drying method. The soil samples were brought back to the laboratory; plant roots and other impurities were removed, and the percentage of soil moisture in weight was measured (Lu et al., 2019). The soil bulk density was measured using a soil bulk sampler (Soil bulk sampler, Model JC-8028, Juchuang, Qingdao, China) for every soil sample. The soil $\mathrm{pH}$ was measured using a $\mathrm{pH}$ meter ( $\mathrm{pH}$ meter, Model PHS-25, LEICI, Nanjing, China) for every soil sample.

\begin{tabular}{|c|c|c|c|c|c|c|c|c|}
\hline 9 & 8 & 7 & 6 & 5 & 4 & 3 & 2 & 1 \\
MP & MNP & CK & NP & NK & PK & NPK & M & MN \\
\hline 18 & 17 & 16 & 15 & 14 & 13 & 12 & 11 & 10 \\
MNP & M & NK & NPK & CK & NK & PK & MN & MP \\
\hline 27 & 26 & 25 & 24 & 23 & 22 & 21 & 20 & 19 \\
M & MN & NPK & PK & NP & NK & CK & MP & MNP \\
\hline 36 & 35 & 34 & 33 & 32 & 31 & 30 & 29 & 28 \\
MN & MP & PK & NK & NPK & CK & NP & MNP & M \\
\hline
\end{tabular}

Figure 3. Test plot layout. $M$, organic fertilizer; $M N$, organic fertilizer combined with nitrogen fertilizer; MP, organic fertilizer combined with phosphate fertilizer; MNP, organic fertilizer combined with nitrogen and phosphate fertilizer; NP, nitrogen fertilizer combined with phosphate fertilizer; $N K$, nitrogen fertilizer combined with potassium fertilizer; $P K$, phosphorus combined with potassium fertilizer; NPK, nitrogen combined with phosphate and potassium fertilizer; $C K$, no-fertilizer control

At the end of the growing season, 3 quadrats $(1 \mathrm{~m} \times 1 \mathrm{~m})$ were harvested in each plot by cutting at the soil surface level; the harvested plants were dried in an oven $\left(75^{\circ} \mathrm{C}\right.$, $24 \mathrm{~h}$ ), weighed, and their value was converted to plot yield. Final crop yield was obtained by harvesting 4 replicates of each treatment. The 2017 millet was harvested on October $12^{\text {th }}$, and the 2018 soybean crop was harvested on October $4^{\text {th }}$. In 2017 , soil moisture content before sowing was measured on April $26^{\text {th }}$, and post-harvest moisture was measured on October $13^{\text {th }}$. In 2018, soil moisture content before sowing was measured on April $20^{\text {th }}$, and post-harvest moisture was measured on October $5^{\text {th }}$.

\section{Index calculations}

The requisite indices were calculated according to the following formulae.

$$
S w=H_{i} \times D_{i} \times B \times 10
$$

where: $\mathrm{Sw}(\mathrm{mm})$ is the sum of soil water stored in different soil layers (Lu et al., 2019); $\mathrm{D}_{\mathrm{i}}\left(\mathrm{g} \mathrm{cm}^{-3}\right)$ is the soil bulk density in different soil layers; $\mathrm{H}_{\mathrm{i}}(\mathrm{cm})$ is the soil depth; and $\mathrm{B}(\%)$ is the percentage of soil moisture in weight. 


$$
E T=W_{1}-W_{2}+P
$$

where: ET (mm) is the water consumption during the crop-growing season (Xu et al., $2020 \mathrm{a}) ; \mathrm{W}_{1}(\mathrm{~mm})$ is the water storage at a soil depth of $0-100 \mathrm{~cm}$ at sowing; $\mathrm{W}_{2}(\mathrm{~mm})$ is the water storage at a soil depth of $0-100 \mathrm{~cm}$ during harvest; $\mathrm{P}(\mathrm{mm})$ is the precipitation measured during the crop growth period.

$$
\mathrm{WUE}={ }^{Y} / E T
$$

where: WUE is water use efficiency $\left(\mathrm{kg} \mathrm{m}^{2} \mathrm{~mm}^{-1}\right)$ (Adimassu et al., 2017); $\mathrm{Y}\left(\mathrm{kg} \mathrm{m}^{2}\right)$ is the yield per unit plot.

\section{Statistical analysis}

One-way ANOVA analysis was used to examine the effects of fertilization treatment on soil water storage, soil WUE, and crop yield $(P<0.05)$. Before the analysis, we performed a normality and homogeneity test of the data. Linear regression analysis was used to show the relationship between crop yield and soil WUE. All statistical analyses were performed using the software package IBM SPSS Statistics (version 26.0). The differences between the treatments were calculated using the least significance difference test at a 0.05 probability level. Figures were prepared using Origin 9.0.

\section{Results}

\section{Soil profile water content}

In 2017, before sowing, the soil moisture water content in the $0-10 \mathrm{~cm}$ soil layer of the M, MN, MP, and NK plots was higher than that in the CK plots, while in the 10$100 \mathrm{~cm}$ soil layers the soil moisture water content of all the fertilization treatments was lower than that of the CK (Fig. 4a). The soil moisture water content of all fertilization treatments in the $0-10 \mathrm{~cm}$ soil layer was higher than that of $\mathrm{CK}$ after the crop harvest in 2017 and before sowing in 2018, and the soil moisture water content of all fertilization treatments in the $10-100 \mathrm{~cm}$ soil layers was lower than that of CK (Fig. 4b,c). Furthermore, after the crop harvest in 2018 the soil moisture water content of the M, MN, MP, and NPK treatments in the $0-10 \mathrm{~cm}$ soil layer was higher than that of the CK treatment, and in the 10-100 cm soil layers the soil moisture water content of all the fertilization treatments was lower than that of the CK treatment (Fig. 4d).

\section{Soil water storage}

In 2017, the soil water storage recorded in the CK plots exceeded that found in fertilized plots; it was $1.22-21.11 \mathrm{~mm}$ higher than that of all of the fertilization treatments, both before sowing and after harvest. Meanwhile, the soil water storage of the MN, MP, and MNP plots was higher than that of the other fertilization treatments, both before sowing and after harvest (Fig. 5a). In 2018, the soil water storage of the CK plots was greater than that of the fertilization treatments after harvest; meanwhile, the soil water storage in the MN, MP, MNP, and NPK plots was higher than in the other fertilization treatments, both before sowing and after harvest (Fig. 5b). 

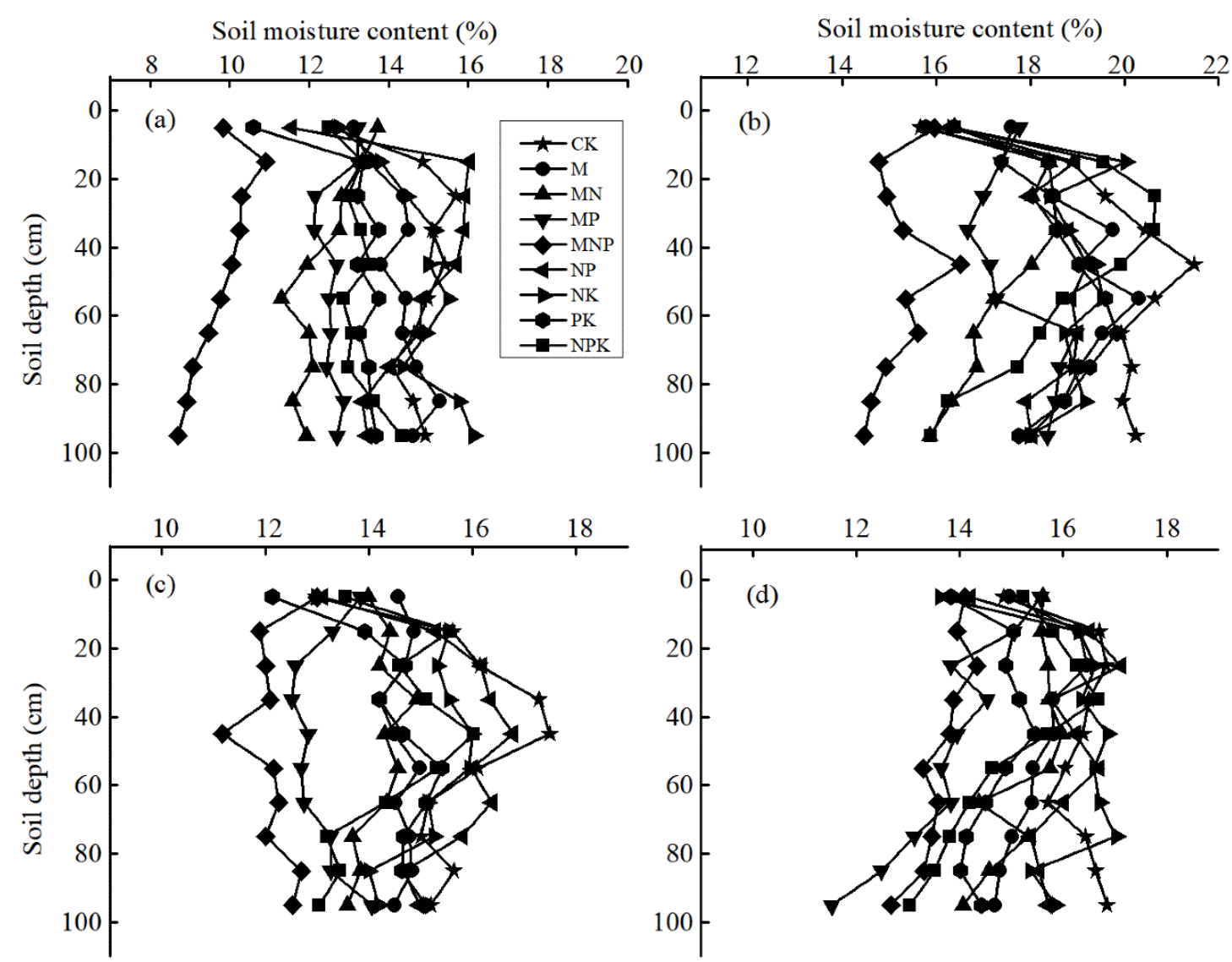

Figure 4. Soil moisture water content (mean) in 2017 before sowing (a), 2017 after harvest (b), 2018 before sowing (c), and 2018 after harvest (d) in different fertilization treatments. Notes: $M$, organic fertilizer; $M N$, organic fertilizer combined with nitrogen fertilizer; $M P$, organic fertilizer combined with phosphate fertilizer; MNP, organic fertilizer combined with nitrogen

and phosphate fertilizer; NP, nitrogen fertilizer combined with phosphate fertilizer; NK, nitrogen fertilizer combined with potassium fertilizer; $P K$, phosphorus combined with potassium fertilizer; NPK, nitrogen combined with phosphate and potassium fertilizer; CK, no-fertilizer control

\section{Crop yield and soil water consumption (ET)}

Overall, higher crop yield was recorded after fertilization. In 2017, the crop yields of the M, MN, MP, MNP, NP, NK, and NPK plots were 15\%, 11\%, 8\%, 21\%,8\%, 5\%, and $11 \%$ greater, respectively, than that after CK treatment. In 2018, the crop yield of the M, MN, MP, MNP, NP, NK, and NPK plots was higher than that of the CK plots by $11 \%, 14 \%, 15 \%, 19 \%, 7 \%, 3 \%$, and $11 \%$, respectively (Fig. 6).

In 2017, the water consumption (ET) recorded in the CK plots lower than the other fertilized plots; approximately $12.83-47.73 \mathrm{~mm}$ lower than that of all fertilization treatments. Meanwhile, the soil water consumption of the MN, MP, and MNP plots was higher than that of other fertilization treatments, both before sowing and after harvest (Fig. 7). In 2018, the soil water consumption of the CK plots was lower than that of the fertilization treatments; meanwhile, the soil water storage in the MN, MP, MNP, and NPK plots was higher in other fertilization treatments (Fig. 7).

The linear regression showed that the ET was significantly positively correlated with crop yield $\left(\mathrm{R}^{2}=0.846, \mathrm{P}<0.001\right)($ Fig. 8$)$. 


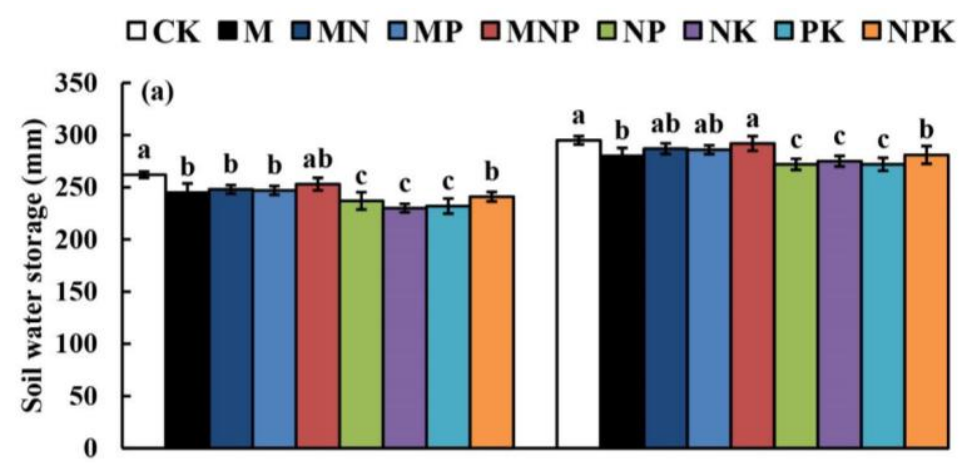

Before sowing

After harvest

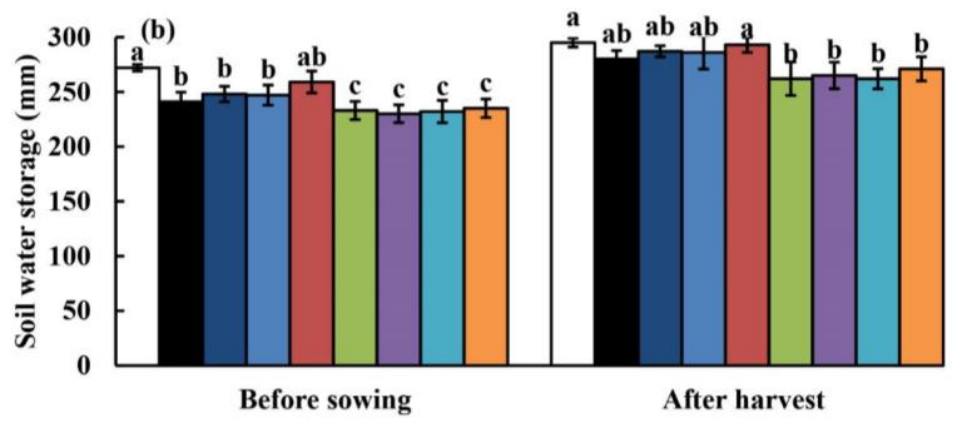

Figure 5. The soil water storage (mean \pm standard error) recorded in 2017 (a) and 2018 (b) for the different fertilization treatments. Values that are in the same column and the same year followed by different letters indicate significant differences at the $5 \%$ level (Duncan $P<0.05$ ). $M$ stands for organic fertilizer; $M N$, organic fertilizer combined with nitrogen fertilizer; $M P$, organic fertilizer combined with phosphate fertilizer; MNP, organic fertilizer combined with nitrogen and phosphate fertilizer; NP, nitrogen fertilizer combined with phosphate fertilizer;

$N K$, nitrogen fertilizer combined with potassium fertilizer; $P K$, phosphorus combined with potassium fertilizer; NPK, nitrogen combined with phosphate and potassium fertilizer; $C K$, nofertilizer control

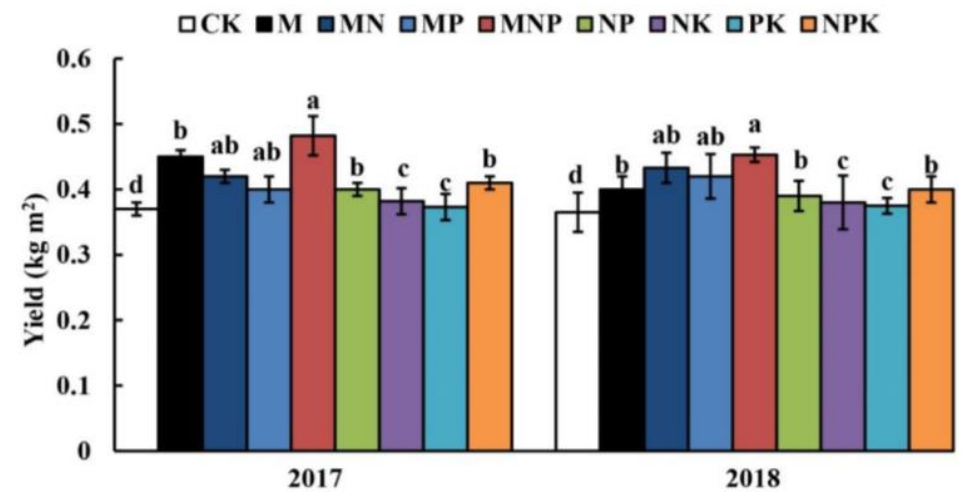

Figure 6. The crop yield (mean \pm standard error) at different fertilization treatments in 2017 and 2018. Values in the same column and the same year followed by different letters indicate significant differences (Duncan $P<0.05$ ). $M$ stands for organic fertilizer; $M N$, organic fertilizer combined with nitrogen fertilizer; $M P$, organic fertilizer combined with phosphate fertilizer; MNP, organic fertilizer combined with nitrogen and phosphate fertilizer; NP, nitrogen fertilizer combined with phosphate fertilizer; $N K$, nitrogen fertilizer combined with potassium fertilizer; $P K$, phosphorus combined with potassium fertilizer; NPK, nitrogen combined with phosphate and potassium fertilizer; $C K$, no-fertilizer control 


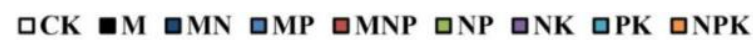

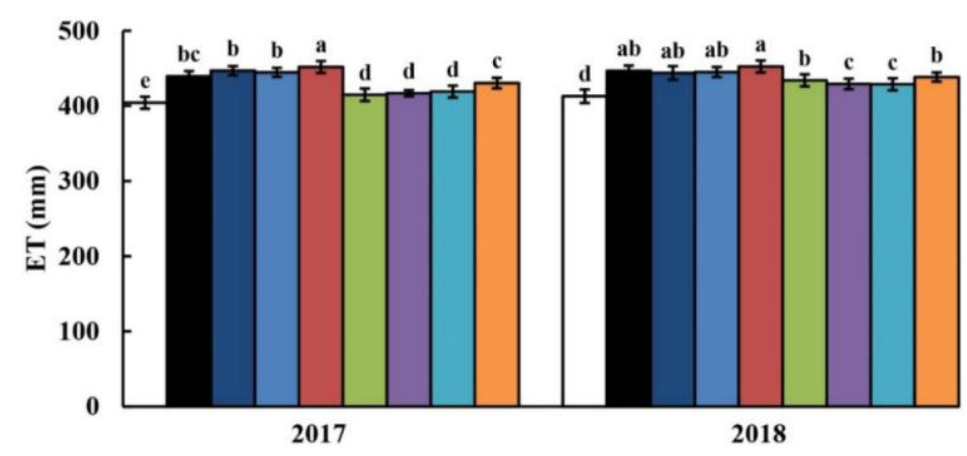

Figure 7. Water consumption (ET) (mean \pm standard error) at different fertilization treatments in 2017 and 2018. Values in the same column and year followed by different letters indicate significant differences (Duncan $P<0.05$ ). $M$, organic fertilizer; $M N$, organic fertilizer combined with nitrogen fertilizer; MP, organic fertilizer combined with phosphate fertilizer; $M N P$, organic fertilizer combined with nitrogen and phosphate fertilizer; NP, nitrogen fertilizer combined with phosphate fertilizer; NK, nitrogen fertilizer combined with potassium fertilizer; $P K$, phosphorus combined with potassium fertilizer; NPK, nitrogen combined with phosphate and potassium fertilizer; $C K$, no-fertilizer control

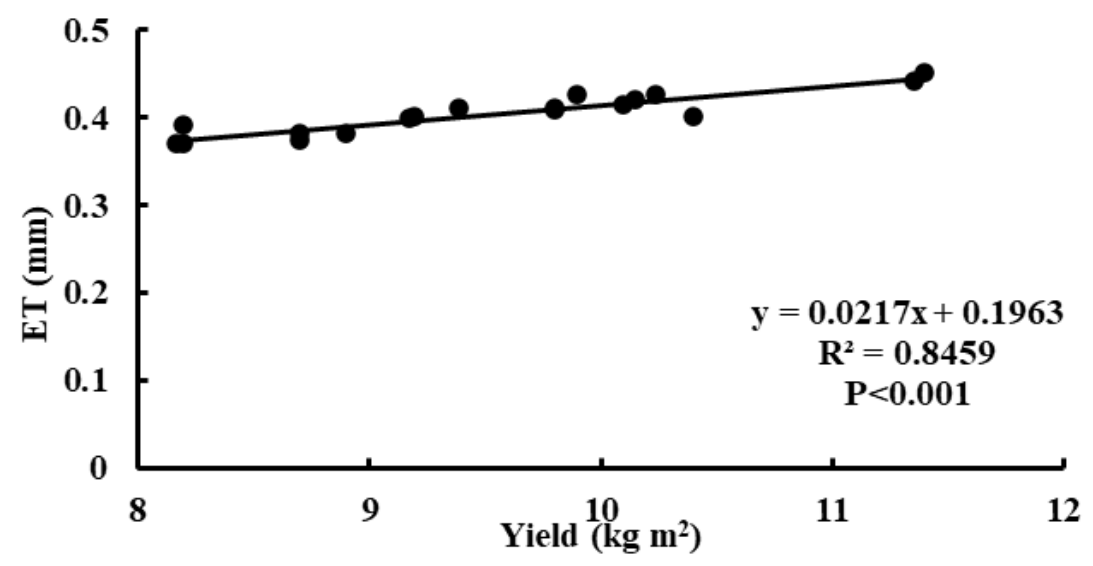

Figure 8. The correlation between crop yield and soil water consumption (ET)

\section{Soil water use efficiency (WUE)}

Overall, higher WUE was recorded after fertilization. In 2017, in comparison to the CK plot, the WUE of the M, MN, MP, MNP, NP, PK, and NPK plots was greater by $21 \%, 23 \%, 26 \%, 39 \%, 12 \%, 6 \%$ and 20\%, respectively (Fig. 9). In 2018, the WUE of the M, MN, MP, MNP, NP, PK, and NPK plots was greater than that of the CK plots by $15 \%, 24 \%, 25 \%, 39 \%, 12 \%, 8 \%$ and 20\%, respectively (Fig. 9).

\section{Discussion}

Improving WUE is a major goal of agricultural development in arid and semi-arid areas. Appropriate fertilizer application can promote crop growth and development, encourage the growth of deep roots, and enhance crop use of deep soil water (Ameen et al., 2019; Tamaki, 1997). We tested whether the application of organic and inorganic 
fertilizers will improve soil WUE and found that fertilization was closely linked to soil water storage and WUE (Samuelson, 2018; Zhang et al., 2019). In 2017 and 2018, soil WUE increased by 6-39\%, and 8-39\%, respectively, compared with the no-fertilization control, supporting Hypothesis 1. However, the soil water content and water storage showed an overall reduction compared with the no-fertilization treatment; this result is in line with those of the previous studies but contradicts Hypothesis 1.

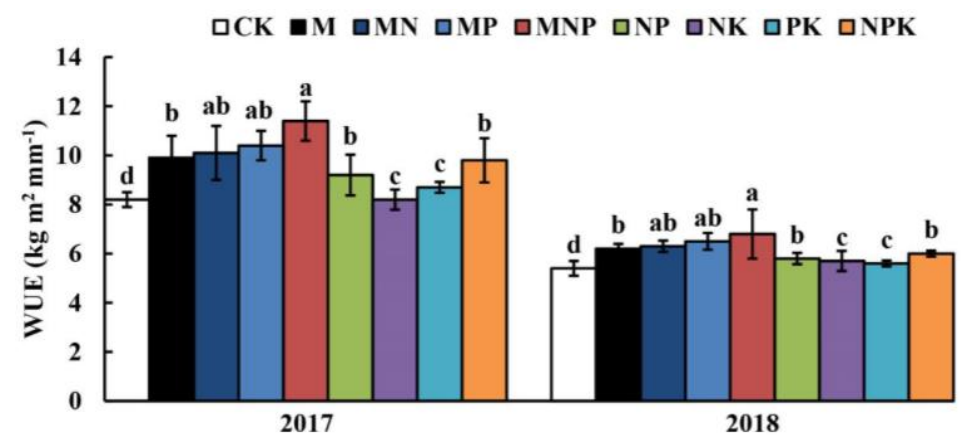

Figure 9. Soil water use efficiency (WUE) (mean \pm standard error) of the different fertilization treatments in 2017 and 2018. Values in the same column and year followed by different letters indicate significant differences (Duncan $P<0.05$ ). $M$, organic fertilizer; $M N$, organic fertilizer combined with nitrogen fertilizer; MP, organic fertilizer combined with phosphate fertilizer; $M N P$, organic fertilizer combined with nitrogen and phosphate fertilizer; NP, nitrogen fertilizer combined with phosphate fertilizer; $N K$, nitrogen fertilizer combined with potassium fertilizer; $P K$, phosphorus combined with potassium fertilizer; NPK, nitrogen combined with phosphate and potassium fertilizer; $C K$, no-fertilizer control

Multiple mechanisms and factors are at play in the effect of fertilization on crop water use. Previous studies have found that soil WUE follows the same changing characteristics as the leaf area index (De et al., 2013; Ibrahim et al., 2015; Krbel, 2012). Firstly, appropriate fertilization treatment can significantly increase the total amount of crop roots, enhance root vitality, and expand the space available to roots to absorb soil moisture and nutrients; it can also increase leaf area, boost the photosynthetic rate, reduce evaporation, and achieve maximum efficiency in the utilization of limited moisture in semi-arid areas (Wang, 2013; Liu et al., 2010). It is because fertilization promotes the vigorous growth of crops that the water consumption of ground evaporation is reduced (Sheoran et al., 2017). Therefore, after fertilization, the rapid growth of the crops increases soil water consumption and decreases soil water storage and content, while soil WUE increases. Secondly, the growth of the vegetation and the expansion of plant stems and leaves after fertilization results in a stronger plant cover on the ground surface, slowing down the water consumption in the form of surface evaporation, which also increases the plant water use. In addition, the abundant rainfall in the late filling stage (Fig. 2) is likely to have enabled the plants to fully exploit the available soil nutrients. This explains why the water consumption of the fertilized plots was significantly greater than that of the unfertilized control.

The ultimate goal of increasing crop WUE is an enhanced yield, which can be achieved when the right balance is struck between the source and sink conditions (Zhang et al., 2019; Amoah et al., 2012). Fertilization is an important agronomic measure for increasing source characteristics such as dry matter accumulation and sink characteristics such as crop yield (Chaab, 2011; Meng et al., 2012). Our results show 
that higher crop yield can be achieved by fertilization. In this study, the yield of plants treated with additional organic and inorganic fertilizers was significantly higher than that of the no-fertilization control. This is in line with the results of previous studies showing an overall increase in dry matter accumulation after fertilization.

Fertilization can enhance crop yield via a variety of pathways. It is known that low soil nutrient availability limit growth (Kurwakumire et al., 2014). Fertilization increases the amount of available nutrients in the soil, boosting the absorption and utilization of soil nutrients by plants. In addition, chlorophyll is essential for photosynthesis, and its content in leaves reflects the level of photosynthesis (Roland et al., 2012). Nutrients are required for chlorophyll production (Wang and Jin, 2007). Appropriate application of fertilizers can increase chlorophyll content in plant tissues, as demonstrated previously (Xu et al., 2020b); this promotes the growth of above-ground parts, thereby increasing biomass accumulation. Some studies have shown that fertilization can achieve higher yields through simultaneously improving cooperatively improving the indicators of crop dry matter accumulation, dry matter transport capacity of vegetative organs, and photosynthetic compound accumulation (Eisvand, 2018).

It is likely that both nutrient availability and water consumption are involved in the enhancement of crop yield observed after the application of fertilizers. This is consistent with our finding of a significant positive correlation between crop yield and soil ET, suggesting that the two occur synergistically after fertilization. Studies have shown that nutrients can increase water uptake, transport, and overall content in plants, thereby increasing yields (Tamaki, 1997). A 2006 study reported that the addition of organic and inorganic fertilizers increased the soil nutrient supply and the soil WUE during the crop growth period, benefitting plant growth and development, enhancing photosynthesis, and thus increasing plant biomass accumulation ( $\mathrm{Li}$ et al., 2018). A positive feedback loop mechanism may be involved: it has been shown that increases in biomass promote transpiration, which indirectly promotes root growth and photosynthesis, thereby further increasing crop yields. Drought and nutrient deficiencies are typical characteristics of the Loess plateau and can have significant negative effects on crop yields (Amoah et al., 2012). Our study provided a preliminary look at the effect of different types of fertilization on crop production and WUE. There is scope for future studies to explore the complex mechanisms that drive the yield changes observed under different fertilization modes.

In recent years, owing to many countries' emphasis on the protection of the ecological environment and the quality and safety of agricultural products, more and more scientists have focused their research on the rational use of organic fertilizers (Sadeghzadeh and Rengel, 2011). We found that the use of organic fertilizers improved soil water efficiency and crop growth more than the use of inorganic fertilizers, which supported Hypothesis 2. One potential reason for this result is that organic fertilizers can improve the functional diversity of microbial communities in crop rhizosphere soils (Cheng et al., 2015; Wang, 2009) and are therefore superior to inorganic fertilizers in terms of their effect on plant nutrient absorption and transformation. For instance, Wang et al. (2012) found that the combined application of NPK fertilizers and organic fertilizer can make crops have improved yields and results in higher yields than NPK fertilizers alone. In addition, some studies have found that the nutrient release of organic fertilizer is slow and thus more helpful for subsequent improvement of soil fertility (Ren et al., 2019). Our results showed that the treatments that increased production and improved water use the most were the 
combination of organic fertilizer with $\mathrm{N}$ and P fertilizer in 2017 and 2018. Further experiments are needed to quantify the economic benefits of organic fertilizer and elucidate its relative effects on different crop species. Additional factors such as ecological and environmental protection, sustainable soil use, and economic output benefits should be comprehensively considered when making definitive recommendations on the application of organic and inorganic fertilizers.

\section{Conclusion}

Our study sheds light onto the effect of organic and inorganic fertilizers on soil water use and agricultural production in rain-fed agricultural areas on the Loess Plateau (China). We examined the variations in soil WUE and crop yield under nine fertilization treatments. Our results revealed that fertilization increases soil WUE and crop yield but decreases soil water storage. The treatments combining organic fertilizer with $\mathrm{N}$ and $\mathrm{P}$ fertilizer had the strongest positive effect on soil WUE and crop yield. Based on our results, we therefore recommend the use of organic fertilizers in arid and semi-arid areas as a method for improving soil WUE and crop yield. Further studies should conduct similar analyses over a longer study period and with different crop species and attempt to elucidate the mechanisms at play in the effect of fertilization on crop yield.

Funding. This research was supported by the National Key Research and Development Program of China (2017YFE0118100), the National Science Foundation of China (41761017), the Natural Science Foundation of Gansu Province (18JR3RE247).

\section{REFERENCES}

[1] Adimassu, Z., Langan, S., Johnston, R., Mekuria, W., Amede, T. (2017): Impacts of soil and water conservation practices on crop yield, run-off, soil loss and nutrient loss in Ethiopia: review and synthesis. - Environ Manag 59: 87-101.

[2] Ameen, A., Liu, J., Han, L., Xie, G. H. (2019): Effects of nitrogen rate and harvest time on biomass yield and nutrient cycling of switchgrass and soil nitrogen balance in a semiarid sandy wasteland. - IND Crop Prod 136: 1-10.

[3] Belay, A., Claassens, A. S., Wehner, F. C. (2002): Effect of direct nitrogen and potassium and residual phosphorus fertilizers on soil chemical properties, microbial components and maize yield under long-term crop rotation. - Biol Fert Soils 35: 420-427.

[4] Chaab, A., Savaghebi, G. R., Motesharezadeh, B. (2011): Differences in the zinc efficiency among and within maize cultivars in a calcareous soil. - Asian J. Agric. Sci 3: 26-31.

[5] Cheng, W., Liu, X., Gao, Y., Zhang, W., Wang, D., Qiu, H., Shen, Q. (2015): Effect of organic fertilizer partially replace chemical fertilizer on functional diversity of potato rhizosphere soil microbial community. - Chinese Journal of Soil Science 46: 1459-1465 (in Chinese with English abstract).

[6] De Kauwe, M. G., Medlyn, B. E., Zaehle, S. (2013): Forest water use and water use efficiency at elevated $\mathrm{CO}_{2}$ : a model-data intercomparison at two contrasting temperate forest FACE sites. - Global Change Biol. 19: 1759-1779.

[7] Eisvand, H. R., Kamaei, H., Nazarian, F. (2018): Chlorophyll fluorescence, yield and yield components of bread wheat affected by phosphate bio-fertilizer, zinc and boron under late-season heat stress. - Photosynthetica 56: 1287-1296. 
[8] Fan, T., Stewart, B., Yong, W., Junjie, L., Guangye, Z. (2005): Long-term fertilization effects on grain yield, water-use efficiency and soil fertility in the dryland of Loess Plateau in China. - Agr. Ecosyst. Environ 106: 313-329.

[9] Hamdy, A., Ragab, R., Scarascia-Mugnozza, E. (2003): Coping with water scarcity: water saving and increasing water productivity. - Irrig. Drain 52: 3-20.

[10] Huang, T., Rung, X., Liu, Q. (2010): Effects of different organic fertilization modes on yield, quality, fertilizer nitrogen utilization of spring maize and nitrogen loss from field. Soils 42: 915- 919.

[11] Ibrahim, A., Abaidoo, R. C., Fatondji, D., Opoku, A. (2015): Hill placement of manure and fertilizer micro-dosing improves yield and water use efficiency in the Sahelian low input millet-based cropping system. - Field Crop Res 180: 29-36.

[12] Guo, Q., Cheng, C., Jiang, H., Liu, B., Wang, Y. (2019): Comparative rates of wind and water erosion on typical farmland at the northern end of the Loess Plateau, China. Geoderma 352: 104-15.

[13] Krbel, R., Campbell, C. A., Zentner, R. P., Lemke, R., Steppuhn, H., Desjardins, R. L., De Jong, R. (2012): Nitrogen and phosphorus effects on water use efficiency of spring wheat grown in a semi-arid region of the Canadian prairies. - Can J Soil Sci 92: 573-587.

[14] Kurwakumire, N., Chikowo, R., Mtambanengwe, F., Mapfumo, P., Snapp, S., Johnston, A. (2014): Maize productivity and nutrient and water use efficiencies across soil fertility domains on smallholder farms in Zimbabwe. - Field Crops Research 164: 136-147.

[15] Laxminarayana, K., John, K. S., Ravindran, C. S., Naskar, S. K. (2011): Effect of lime, inorganic, and organic sources on soil fertility, yield, quality, and nutrient uptake of sweet potato in Alfisols. - Commun Soil Sci Plan 42: 2515-2525.

[16] Li, P., Zhang, J., Qi, X., Du, Z., Guo, W., Zhang, Y., Zhao, Z. (2018): The responses of soil function to reclaimed water irrigation changes with soil depth. - Desalin Water Treat 122: $100-105$.

[17] Liu, Z., Fu, B., Zheng, X., Liu, G. (2010): Plant biomass, soil water content and soil N:P ratio regulating soil microbial functional diversity in a temperate steppe: a regional scale study. - Soil Biol Biochem 42: 445-450.

[18] Lu, J., Yang, M., Liu, M., Lu, Y., Yang, H. (2019): Nitrogen and phosphorus fertilizations alter nitrogen, phosphorus and potassium resorption of alfalfa in the Loess Plateau of China. - J Plant Nutr 42: 2234-46.

[19] Meng, X. Y., Wang, Z. H., Li, F. C., Li, K. Y., Xue, C., Li, S. X. (2012): Effects of soil moisture before sowing and nitrogen fertilization on winter wheat yield and water use on Weibei Plain of Loess Plateau. - Chin. J. Appl. Ecol 23: 369-375 (in Chinese with abstract).

[20] Ren, K., Zhang, X., Li, X., Yu, X., Liu, Z., Wang, G., An, G., Jiang, B. (2019): Effects of organic and chemical fertilizers on nutrient absorption and yield of potato. - Soil fertilizer 6: $1672-3635$.

[21] Roland, K., Lemke, R., Desjardins, R. L., Campbell, C. A.; Zentner, R. P.; Steppuhn, H. (2012): Nitrogen and phosphorus effects on water use efficiency of spring wheat grown in a semi-arid region of the Canadian prairies. - Can. J. Soil Sci 4: 573-587.

[22] Sadeghzadeh, B., Rengel, Z. (2011): Zinc in Soils and Crop Nutrition. - In: Hawkesford, M. J., Barraclough, P. (eds.) The Molecular and Physiological Basis of Nutrient Use Efficiency in Crops. Wiley-Blackwell, Hoboken, NJ, pp. 335-375.

[23] Samuelson, L. J., Kane, M. B., Markewitz, D. (2018): Fertilization increased leaf water use efficiency and growth of Pinus taeda subjected to five years of throughfall reduction. - Can J Forest Res 48: 227-236.

[24] Sheoran, S., Raj, D., Antil, R. S., Mor, V. S., Dahiya, D. S. (2017): Productivity, seed quality and nutrient use efficiency of wheat (Triticum aestivum) under organic, inorganic and integrated nutrient management practices after twenty years of fertilization. - Cereal Res Commun 45: 315-322. 
[25] Tahir, M., Khan, A., Batool, M. (2012): Effect of dairy manure and rice planting methods on yield, soil quality, water-use efficiency, and economics of rice and succeeding wheat crop. - Commun Soil Sci Plan 43: 1897-1914.

[26] Tamaki, M., Tashiro, T., Yamamoto, Y. (1997): Effects of shading and fertilized nitrogen levels on the growth, yield components and physicochemical properties of rice. Japanese Journal of Crop Science 66: 708-709.

[27] Tang, H., Xiao, X., Tang, W., Wang, K., Guo, L., Li, C., Chang, K., Yang, G. (2016): Effects of different fertilization modes and mulching methods on dry matter accumulation and water use efficiency of spring maize. - Journal of Agricultural Science and Technology 18: 93-100.

[28] Wang, H., Jin, J. (2007): Effects of zinc deficiency and drought on plant growth and metabolism of reactive oxygen species in maize (Zea mays L). - Agr. Sci. China 6: 988995.

[29] Wang, H., Liu, R. L., Jin, J. Y. (2009): Effects of zinc and soil moisture on photosynthetic rate and chlorophyll fluorescence parameters of maize. - Biol. Plantarum 53: 191-194.

[30] Wang, J., Mao, H., Zhao, H., Huang, D., Wang, Z. (2012): Different increases in maize and wheat grain zinc concentrations caused by soil and foliar applications of zinc in Loess Plateau. - China. Field Crop. Res 135: 89-96.

[31] Wang, J., Liu, W., Dang, T., Sainju, U. M. (2013): Nitrogen fertilization effect on soil water and wheat yield in the Chinese Loess Plateau. - Agron J 105: 143-149.

[32] Wang, X., Jia, Z., Liang, L., Yang, B., Ding, R., Nie, J., Wang, J. (2016): Impacts of manure application on soil environment, rainfall use efficiency and crop biomass under dryland farming. - Sci rep-UK 6.

[33] Wu, R. Y., Lawes, R., Oliver, Y., Fletcher, A., Chen, C. (2019): How well do we need to estimate plant-available water capacity to simulate water-limited yield potential? - Agr. Water Manage 212: 441-447.

[34] Xu, H., Qu, Q., Lu, B., Li, P., Xue, S., Liu, G. (2020a): Response of soil specific enzyme activity to vegetation restoration in the Loess hilly region of China. - Catena 191: 104564.

[35] Xu, H., Wang, X., Qu, Q., Zhai, J., Song, Y., Qiao, L., Liu, G., Xue, S. (2020b): Cropland abandonment altered grassland ecosystem carbon storage and allocation and soil carbon stability in the Loess Hilly Region, China. - Land Degrad. Dev. DOI: 10.1002/ldr.3513.

[36] Xue, F., Yan, T., Qiao, J., Yang, L. (2009): Economic and environmental benefits of lower fertilizer application rate in paddy fields in Taihu Area. - Journal of Ecology and Rural Environment 25: 26-31, 51.

[37] Yan, W., Zhong, Y., Shangguan, Z. (2015): The relationships and sensibility of wheat $\mathrm{C}: \mathrm{N}: \mathrm{P}$ stoichiometry and water use efficiency under nitrogen fertilization. - Plant Soil Environ 61: 201-207.

[38] Zhang, K., Greenwood, D. J., White, P. J., Burns, I. G. (2007): A dynamic model for the combined effects of $\mathrm{N}, \mathrm{P}$ and $\mathrm{K}$ fertilizers on yield and mineral composition; description and experimental test. - Plant Soil 298: 81-98.

[39] Zhang, Y., Wang, R., Wang, H., Wang, S., Wang, X., Li, J. (2019): Soil water use and crop yield increase under different long-term fertilization practices incorporated with two-year tillage rotations. - Agr Water Manage 221: 362-370. 